\title{
Prenylated Xanthone and Rubraxanthone with Antiplatelet Aggregation Activity in Human Whole Blood Isolated from Garcinia griffithii
}

\author{
KHALED A.A. ALKADI ${ }^{1}$, AISHAH ADAM ${ }^{1}$, MUHAMMAD TAHA ${ }^{2}$, \\ MIZATON HAZIZUL HASAN ${ }^{1}$ and SYED ADNAN ALI SHAH ${ }^{1,2 *}$
}

${ }^{1}$ Faculty of Pharmacy, Universiti Teknologi MARA (UiTM), Puncak Alam Campus, 42300 Bandar Puncak Alam, Selangor Darul Ehsan, Malaysia.

${ }^{2}$ Atta-ur-Rahman Institute for Natural Products Discovery, Universiti Teknologi MARA (UiTM), Puncak

Alam Campus, 42300 Bandar Puncak Alam, Selangor Darul Ehsan, Malaysia.

${ }^{*}$ Corresponding author E-mail: syedadnan@ salam.uitm.edu.my/benzene301@yahoo.com

http://dx.doi.org/10.13005/ojc/290404

(Received: October 10, 2013; Accepted: November 22, 2013)

\begin{abstract}
Phytochemical studies on the methanolic extract of the leaves of Garcinia griffithii (Guttiferae) afforded two known xanthones derivatives, 1,3,5,6-Tetrahydroxy-7-(3-methylbut-2-enyl)xanthone (1) and Rubraxanthone (2). The structures of these xanthones derivatives were determined on the basis of extensive spectroscopic data interpretation and comparison with data reported in the literature. In an in vitro test, compound 1 and 2 showed the ability to inhibit platelet aggregation in human whole blood which induced by arachidonic acid (AA), adenosine diphosphate (ADP) and collagen.
\end{abstract}

Key words: Garcinia griffithii, Platelet aggregation, Impedance Method, NMR spectroscopy, HMBC correlations.

\section{INTRODUCTION}

Plant secondary metabolites are a group of naturally occurring compounds classes biosynthesized by differing biochemical pathways whose plant content and regulation is strongly susceptible to environmental influences and to potential herbal predators. From ancient to modern times, herbs and plants have been used as medicinal agents, first only on a folkloric basis and later developed on a scientific basis. Natural products of plant origin offered a wide variety of bioactive compounds that could meet the demand for base compounds of drugs ${ }^{1}$. A large proportion of the drugs used in modern medicine were either directly isolated from plants or synthetically modified from a lead compound of natural origin. Drug discovery is an iterative process of lead discovery (i.e. isolation of bioactive lead compounds from these natural sources) coupled with lead improvement (rational design and synthesis of new analogues to improve pharmacological profiles) and natural products play an important role in drug development programs of pharmaceutical industry. Over $50 \%$ of all modern clinical drugs are of natural product origin and higher plants as source of medicinal compounds continue 
to play a dominant role in maintenance of human health since antiquities ${ }^{2-8}$.

Guttiferae (Clusiaceae) plant species have been proven a rich source of bioactive compounds. The family Guttiferae numbers over 1000 species mainly confined to the tropics. Garcinia belongs to Guttiferae (Clusiaceae) family and is a large genus of polygamous trees or shrubs, distributed in the tropical Asia, Africa and Polynesia 9-11. The genus Garcinia consists of 180 species and about 30 species occur in India. For the last several years, chemical investigations of various Garcinia species attracted the attention of chemists and have been extensively investigated from phytochemical and biological points of view due to the interesting biological properties of many of its species. Garcinia species are a rich source of secondary metabolites including xanthones, flavonoids, benzophenones, lactones and phenolic acids and a variety of simple and complex bioactive molecules have been isolated fromthe different parts of African and south east Asian Garcinia species. Phytochemical investigation of the fruits, stem barks, seeds, leaves and roots of different Garcinia species have resulted in the isolation of complex molecules including xanthones, prenylated xanthones, prenylated benzophenones, flavonoids, lactones and triterpenes 9-19. As part of a phytochemical study of South East Asian plants, herein we report the purification, structure characterization, and biological testing of two known xanthones derivatives 1 and 2 (Figure 1), which are common to G. griffithii collected from Negeri Sembilan, Malaysia.

\section{MATERIAL AND METHODS}

\section{General experimental procedures}

Melting points were determined on a Yanaco MP-S3 apparatus. UV spectra were measured on a Shimadzu UV 240 spectrophotometer. JASCO DIP-360 Digital polarimeter was used to measure the optical rotations in chloroform by using $10 \mathrm{~cm}$ cell tube. FTIR-8900 Spectrophotometer was used to record IR spectra in $\mathrm{CHCl}_{3}$. The $1 \mathrm{H}-\mathrm{NMR}$ and $2 \mathrm{D}$ NMR spectra were recorded on a Bruker Avance III 500 Ascend spectrometer using BBO probe, while 13C-NMR spectra were recorded on Bruker Avance III 500 Ascend spectrometer operating at $125 \mathrm{MHz}$ using $\mathrm{CDCl}_{3}$ as solvent. Chemical shifts were reported in $\delta$ (ppm), relative to SiMe4 as internal standard, and coupling constants $(\mathrm{J})$ were measured in $\mathrm{Hz}$. The El-MS and HREIMS were measured on Jeol HX 110 mass spectrometer. TLC was performed on Si gel precoated plates (PF254, $20 \times 20,0.25 \mathrm{~mm}$, Merck, Germany). Ceric sulphate in $10 \% \mathrm{H}_{2} \mathrm{SO}_{4}$ spraying reagent was used for the staining of compounds on TLC. All reagents used were of analytical grades 18 .

\section{Plant material}

The leaves of Garcinia griffithii (Guttiferae) was collected from Pasoh, Negeri Sembilan, Malaysia in September 2012. A voucher specimens (MT29 \& MT31) were deposited in the herbarium of the Herbarium of the Forest Research Institute Malaysia (FRIM), Kepong, Malaysia.

\section{Extraction}

Dried leaves of Garcinia griffithii (Guttiferae) was extracted under reflux with $\mathrm{MeOH}$ for 6-8 hrs and filter it. Obtained $\mathrm{MeOH}$ extract was fractionate through vacuum liquid chromatography (VLC) technique using different polarity. Evaporation of the respective solvents and purified the compounds through Preparative thin layer chromatography 18.

\section{Impedance Method}

Whole blood $(1 \mathrm{ml})$ diluted with buffer saline (1:1) was incubated with samples $5 \mu \mathrm{l}$,in DMSO) at $37^{\circ} \mathrm{C}$ for $2 \mathrm{~min}$. After which collagen $(2 \mu \mathrm{g} / \mathrm{ml})$, ADP $(10 \mu \mathrm{M}), \mathrm{AA}(0.5 \mathrm{mM})$ was added to initiate aggregation. The platelet aggregation was measured by whole blood Lumi-Aggregometer (Chrono-Log Corp.Haver-town,PA). The results of aggregation in whole blood was determined after $5 \mathrm{~min}$. as the increase in impedance across a pair of electrodes placed in the blood sample by comparison to that of control group impedance. To eliminate the effect of the solvent on the aggregation, blood with $0.5 \%$ DMSO was used as the control ${ }^{18}$. The percentage inhibition of platelet aggregation was calculated as:

$$
\% \text { Inhibition }=1-\frac{(\text { aggregation of sample })}{(\text { aggregation of control })} \times 100
$$

\section{RESULTS AND DISCUSSION}

\section{Phytochemical investigation}

Dried leaves of Garcinia griffithii (Guttiferae) 
Table 1: Percentage inhibition of isolated compounds (1-2) from Guttiferae species on platelet aggregation in human whole blood induced by arachidonic acid (AA) $(0.5 \mathrm{mM})$, collagen $(2 \mu \mathrm{g} / \mathrm{mL})$, and adenosine diphosphate (ADP) (10 $\mu \mathrm{M})$

\begin{tabular}{lllll}
\hline Compounds name & $\begin{array}{l}\text { Concentration } \\
(\boldsymbol{\mu g} / \mathrm{ml})\end{array}$ & AA & COLLAGEN & ADP \\
\hline 1,3,5,6-Tetrahydroxy-7-(3- & 100 & $100 \pm 0.00$ & $62.3 \pm 0.71 \mathrm{c}$ & $100 \pm 00 \mathrm{a}$ \\
methylbut-2-enyl)xanthon (1) & 50 & $62.5 \pm 0.7$ & $42.5 \pm 1.4$ & $65.6 \pm 0.45$ \\
& 25 & $45.1 \pm 1.4$ & $22.8 \pm 0.7$ & $30.8 \pm 0.71$ \\
& 12.5 & $25.2 \pm 0.7$ & $6.7 \pm 1.3$ & $16.1 \pm 0.7$ \\
Rubraxanthone (2) & 100 & $57.8 \pm 0.7$ & $100 \pm 00 \mathrm{a}$ & $100 \pm 00 \mathrm{a}$ \\
& 50 & $44.6 \pm 0.48$ & $91.3 \pm 1.5$ & \\
& $66.6 \pm 0.45$ & & & $30.4 \pm 0.85$ \\
& 25 & $24.1 \pm 1.2$ & $65.3 \pm 061$ & \\
\hline
\end{tabular}

Table 2: IC50 values ( $\mu \mathrm{M})$ of isolated compounds (1-2) on platelet aggregation induced by arachidonic acid (AA) $(0.5 \mathrm{mM})$, Collagen $(2 \mu \mathrm{g} / \mathrm{ml})$, and adenosine diphosphate. (ADP) (10 $\mu \mathrm{M})$

\begin{tabular}{llll}
\hline Compounds & AA & Collagen & ADP \\
\hline 1,3,5,6-Tetrahydroxy-7-(3-methylbut-2-enyl)xanthon(1) & $211.1 \pm 2.9$ & $48.1 \pm 2.7$ & $84.6 \pm 2.1$ \\
Rubraxanthone (2) & $114.9 \pm 3.1$ & $229.2 \pm 5.1$ & $107.4 \pm 4.8$ \\
Aspirin & $27.5 \pm 2.8$ & - & - \\
\hline
\end{tabular}

was extracted under reflux with $\mathrm{MeOH}$ for 6-8 hrs and filter it. Obtained $\mathrm{MeOH}$ extract was fractionate through vacuum liquid chromatography (VLC) technique using different polarity. Phytochemical investigations have revealed two known xanthones derivatives, 1,3,5,6-Tetrahydroxy-7-(3-methylbut-2enyl)xanthone (1) and Rubraxanthone (2) (Figure 1). All spectroscopic data described below were showed excellent agreement with the previously published results ${ }^{20-22}$. These structures were confirmed by further analysis of the HMBC correlations as shown in Figure 2 and 3.

1,3,5,6-Tetrahydroxy-7-(3-methylbut-2-enyl) xanthone (1) was obtained as a yellow faint powder (11 mg); EIMS for $\mathrm{C} 18 \mathrm{H} 16 \mathrm{O} 6 \mathrm{~m} / \mathrm{z}$ (rel.int.): 328[M] +; 1H NMR (CD3OD, $500 \mathrm{MHz}$ ): $\delta$ 1.664, 1.786, $3.301,3.314,4.884,5.226,5.240,5.255,6.473$, 6.854, 6.872, 7.563, 7.581; 13C NMR (CD3OD, 150 $\mathrm{MHz}): \delta 16.733,21.001,24.788,93.132,101.847$, $110.670,112.372,113.853,116.350,122.462$,
$130.746,132.380,146.428,151.574,155.983$ 160.289, 163.248, 180.671; APT (CD3OD, $150 \mathrm{MHz}$ ) : 18.0346, 26.0938 (Me $\times 2), 94.4676,113.7592$, 117.6359, $123.6918(\mathrm{CH} \times 4), 22.2860(\mathrm{CH} 2)$, 103.1002, 111.9776, 115.0591, 132.1181, 133.723, 147.7166, 153.0461, 157.2899, 161.5412, 164.6074, $181.9876(\mathrm{C} \times 11)^{20-22}$.

Rubraxanthone (2) was obtained as a yellow crystal (11 mg); EIMS for $\mathrm{C}_{24} \mathrm{H}_{26} \mathrm{O}_{6} \mathrm{~m} / \mathrm{z}$ (rel. int.): 410[M]+; $1 \mathrm{H}$ NMR (CD $\mathrm{OD}, 500 \mathrm{MHz}$ ): $\delta 1.51$ (3H,s,3'-Me), 1.54(3H,s,8'-Me), 1.80(3H,s,3'-Me), $1.95\left(2 \mathrm{H}, \mathrm{t}, 4^{\prime} \mathrm{CH}_{2}\right), \quad 2.02\left(2 \mathrm{H}, \mathrm{m}, 5^{\prime}-\mathrm{CH}_{2}\right), 3.76(3 \mathrm{H}, \mathrm{s}$, $\mathrm{OCH} 3), 4.04\left(2 \mathrm{H}, \mathrm{d}, 1^{\prime}-\mathrm{CH}_{2}\right), 5.01(1 \mathrm{H}, \mathrm{t}, 2 \mathrm{H}), 5.21(1 \mathrm{H}$, t, H6'), 6.09(1H,d,2,1,H7), 6.18(1H,d,2,1,H5); 13C NMR (CD $\left.{ }_{3} \mathrm{OD}, 150 \mathrm{MHz}\right): \delta 181.8$ (C9), 164.7 (C8), $163.5\left(\mathrm{C}_{6}\right), 157.2(\mathrm{C} 10 \mathrm{a}), 156.8(\mathrm{C} 4 \mathrm{a}), 155.5(\mathrm{C} 3)$, 143.7(C2), 137.4(C1), 134.2(C3'), 130.8(C7'), 124.2(C6'), 124.0(C2'), 110.9(C9a), 102.7(C8a), 97.6(C7), 92.8(C5), 39.6(C4'), 26.3(C1'), 25.8(10'), 16.5(7'-Me), 15.4(3'-Me $)^{20-22}$. 

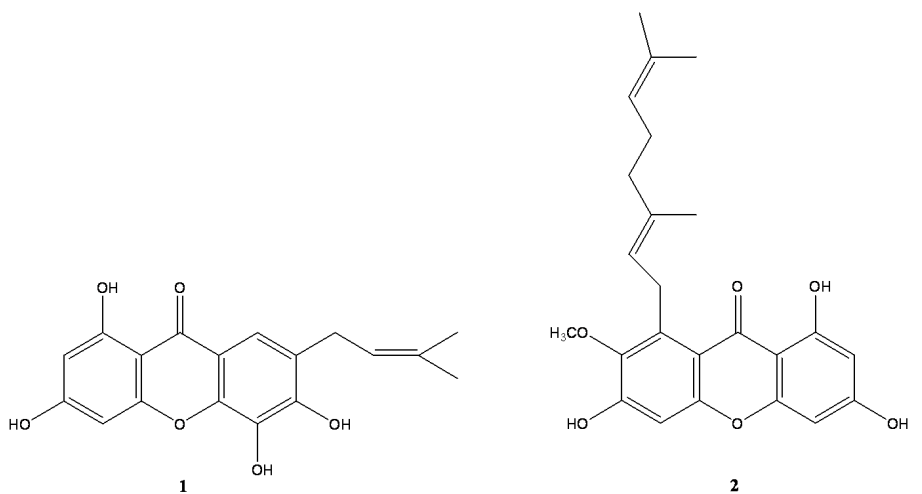

Fig. 1: Chemical structures of secondary metabolites 1 and 2 isolated from leaves of Garcinia griffithii (Guttiferae)

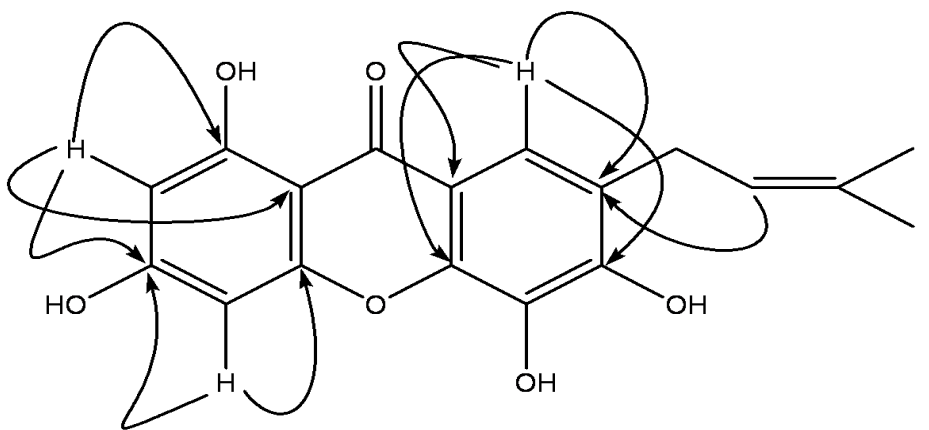

Fig. 2: HMBC correlations of compound 1

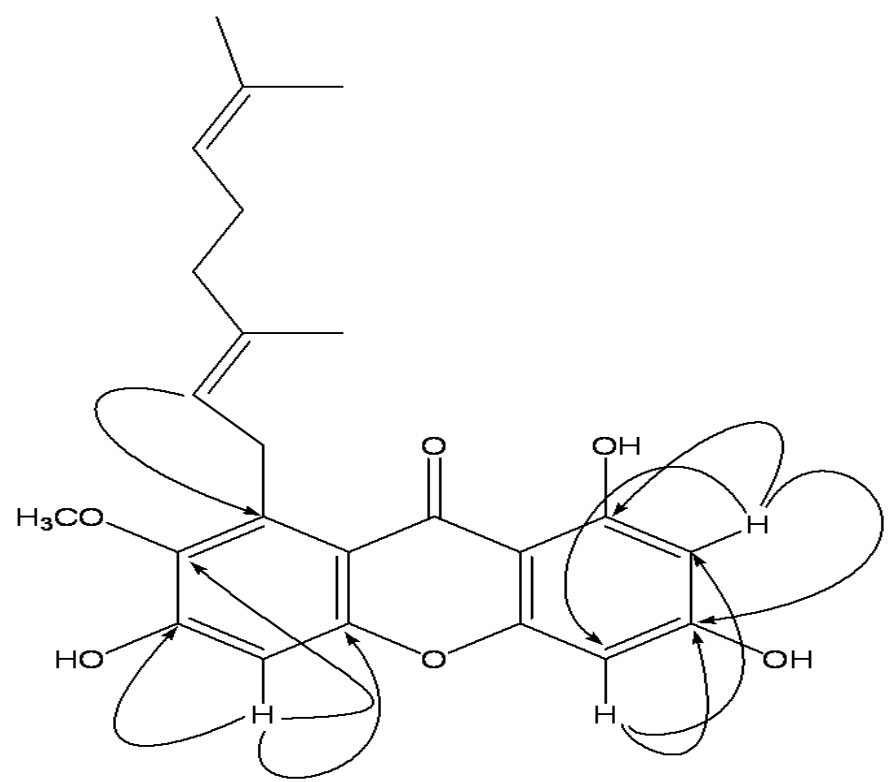

Fig. 3: HMBC correlations of compound 2 


\section{Antiplatelet aggregation activity}

The effect of the isolated secondary metabolites (1-2) from Garcinia griffithii (Guttiferae) has been investigate against platelet aggregation test. Each sample was measured in triplicate oneway analysis of variance (ANOVA) was used for multiple comparison, the IC50 values, that is, the concentration of the compounds required to inhibit aggregation by $50 \%$, were obtained from at least three determinations7. Methanol extracts of Garcinia griffithii (Guttiferae) showed strong antiplatelet aggregation activity at $100 \mu \mathrm{g} / \mathrm{ml}$ in human whole blood in vitro. Both 1, 3, 5, 6-Tetrahydroxy-7-(3methylbut-2-enyl)xanthone (1) and Rubraxanthone
(2) showed marked inhibitory effect on platelet aggregation caused by the three inducers. The IC50 value for 1,3,5,6-Tetrahydroxy-7-(3-methylbut2-enyl)xanthone (1) was 211.1 \pm 2.9 AA, 48.1 \pm 2.7 Collagen, 84.6 \pm 2.1 ADP and the IC50 value for Rubraxanthone (2) was $114.9 \pm 3.1$ AA, $229.2 \pm 5.1$ Collagen, 107.4 \pm 4.8 ADP, respectively (table 1 \& table 2).

\section{ACKNOWLEDGMENTS}

The authors are grateful to Faculty of Pharmacy, Universiti Teknologi MARA (UiTM), Puncak Alam campus for financial support.

\section{REFERENCES}

1. S. Kumar, S. Sharma, S. K. Chattopadhyay, Fitoterapia. 89: 86-125 (2013).

2. J.T. Baker, R.P. Borris, B. Carte, G.A. Cordell, D.D. Soejarto, G.M. Cragg, J Nat Prod. 58: 1325-57 (1995).

3. G.A. Cordell. Phytochem. 40: 1585-612 (1995).

4. M. Stuffness, J. Douros, J Nat Prod. 45: 1-14 (1982).

5. G.J. Bennett, H.H. Lee, Phytochem. 28: 96798 (1989).

6. The Wealth of India; (Raw Materials), Vol IV. New Delhi, India: CSIR; 99: (1985).

7. V. Babu, S.M. Ali, S. Sultana, M. Ilyas. Phytochem. 27: 3332-5 (1988).

8. K.R. Gustafson, J. W. Blunt, M.H.G. Munro, R.W. Fuller, T.C. Mckee, J.H. Cardellina II. Tetrahedron. 48: 10093-102 (1992).

9. O. Thoison, J. Fahy, V. Dumontet, A. Chaironi, C. Riche, M.V. Tri, J Nat Prod. 63: 441-6 (2000).

10. H. Minami, M. Kinoshita, Y. Fukuyama, M. Kodama, T. Yoshizawa, M. Suguira, Phytochem. 36: 501-6 (1994).

11. P.G. Waterman, E.G. Crichton, Planta Med. 40: $351-5$ (1980).

12. P.G. Waterman, E.G. Crichton, Phytochem.
19: 2723-6 (1980).

13. J. Kosin, N. Ruangrunsgi, C. Ito, H. Furukawa. Phytochem. 47: 1167-8 (1998).

14. M. linuma, T. Ito, R. Miyake, H. Tosa, T.Tanaka, V. Chelladurai, Phytochem. 47: 1169-70 (1998).

15. J. Asano, K. Chiba, M. Tada, T. Yoshi, Phytochem. 41: 815-20 (1996).

16. V. Rukachaisirikul, M. Kamkaew, D. Sukavisit, S. Phongpaichit, P. Sawangchote, W.C. Taylor, J Nat Prod. 66: 1531-5 (2003).

17. K. Likhitwitayawuid, T. Phadungcharoen, J. Krungkrai. Planta Med. 64: 70-2 (1998).

18. K.A.A. Alkadi, A. Adam, M. Taha, M.H. Hasan, S.A.A. Shah, Orient. J. Chem. 29(3): 871-875 2013.

19. A.E. Hay, M.C. Aumond, S. Mallet, V. Dumontet, M. Litaudon, D. Rondeau, J Nat Prod. 67: 707-9 (2004).

20. C.M. Teng, C.N. Lin, F.N. Ko, K.L. Cheng, T.F. Huang, Biochem Pharmacol. 38: 3791-3795 (1989).

21. C.N. Lin, S.S. Liou, F.N. Ko, C.M. Teng, J Pharm Sci. 82: 11-16 (1993b).

22. M.I. Chung, J.R.Weng, J.P.Wang, C.M. Teng, C.N. Lin, Planta Med. 68: 25-29 (2002). 